\title{
ARQUÍLOCO 191 E 193 IEG $^{1}$ \\ ARCHILOCHUS 191 AND 193 IEG
}

\author{
Paula da Cunha Corrêa ${ }^{2}$
}

Resumo: Neste artigo são examinados os fragmentos 191 e 193 IEG de Arquíloco: traduções, fortuna crítica, e imagens que associam Eros com a morte e o amante com o guerreiro.

Palavras-chave: Arquíloco; poesia jâmbica grega; Eros.

Abstract: This paper examines translations, the critical fortune and images that associate Eros with death and the lover with the warrior in Archilochus 191 and 193 IEG.

Keywords: Archilochus; greek iambic poetry; Eros.

\begin{abstract}
Arquíloco Fr. 191 IEG²: Estobeu 4. 20.43

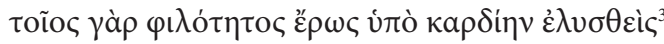

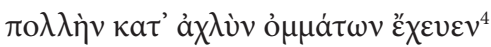

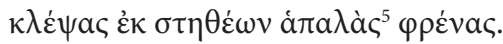

pois tal desejo de amor, enroscado sob o coração, muita névoa sobre os olhos vertia, furtando o frágil juízo do peito.
\end{abstract}

Estobeu 4. 20.43, fonte única desse fragmento, cita os versos de Arquíloco no capítulo Sobre Afrodite. Mas é Eros, não a deusa, que figura na citação. Trata-se de uma vigorosa descrição dos efeitos do desejo de amor (Eros) sobre corpo e alma que muitos, desde Liebel (1812: 170), apontaram

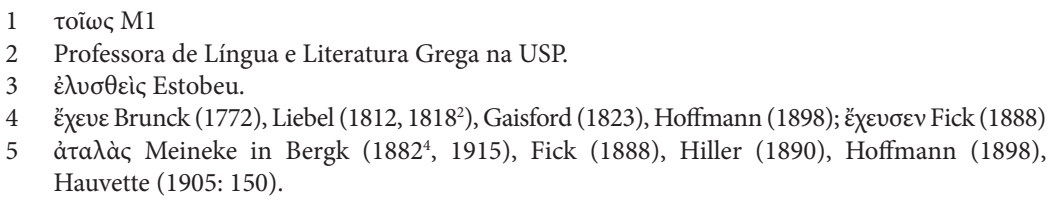


como precursora de versos como os de Safo. Esse fragmento, juntamente com o $193 I_{E G^{2}}$ examinado a seguir, figura entre os mais célebres da poesia amatória de Arquíloco.

Por questões métricas, alguns acreditavam que $191 I E G^{2}$ fazia parte de um grande epodo no qual estariam reunidos todos os fragmentos supérstites de Arquíloco que seguem o mesmo esquema rítmico (188-192 IEG $\left.{ }^{2}\right)^{6}$. Porém, não se sabe quantos poemas Arquíloco compôs nesse ritmo e nada indica que todos os versos metricamente semelhantes que nos restaram pertencessem a um só poema.

Campbell (1983: 5) acreditava que "alguns fragmentos de Arquíloco procuram expressar, pela primeira vez, o sentir-se vítima de desejo erótico"”. Mas não há como saber quando foi "a primeira vez". Se tratar de dores e desejos dos indivíduos é um traço genérico privilegiado pela poesia "lírica", a épica não está isenta deles, embora a sua importância, nesse gênero, seja secundária ${ }^{8}$.

Como resultado dessa abordagem, nota-se que, no fragmento $191 \mathrm{IEG}{ }^{2}$ de Arquíloco, apesar de a descrição ser feita inteiramente na terceira pessoa e de nada no texto nos indicar quem é o sujeito, a maioria dos tradutores insere em suas versões, arbitrariamente, pronomes de primeira pessoa inexistentes no original, presumindo tratar-se de um discurso em que o poeta "fala de si": Hauvette (1905: 230 "...mon coeur...mes yeux.... ma poitrine ma ...raison"), veja o mesmo em Lasserre e Bonnard (1958), Tarditi (1968), Kirkwood (1974: 41), Fränkel (1975: 144), Barron e Easterling (1985: 82), Carson (1986: 46), Adrados (19903) e Snell (19937). No vernáculo, Faria Coimbra (1941: 87) traduziu: "Tal ardência de amor me entrara no peito... tirando-me de brandos sentimentos...), e Martins de Jesus (2008): "Tal foi o desejo de amor, que me cobriu o coração... sobre meus olhos ... arrebatando do meu peito...”).

6 Tetrâmetro dactílico + itifálico (= o chamado asinarteto) / trimetro jâmbico catalético. Trata-se de um esquema métrico semelhante ao empregado por Horácio na Ode 1.4. Para Lasserre (1950: 50, Lasserre e Bonnard 1958), o oitavo epodo de Arquíloco incluiria os fragmentos 188. 1-2, 66, 205, 189, 252, 206-208, 192, 190, 191 (+ 246, 247 L), $209 I E G^{2}$ (cf. Adrados 19903). West (1974: 134) julgava possível que os fragmentos $188-191 I E G^{2}$ formassem um poema de ódio, cujos ecos ouviríamos em Horácio Ep. 8, Carm. 4.13 e Meleagro 60 = AP 5. 204. Bowie (1987: 1323) acrescenta a esse conjunto o fragmento $192 I E G^{2}$.

7 Veja também Burnett (1983: 80): "Archilochus is not, of course, a poet of romantic love, but he does have some lines that begin to sound, in spite of their traditional phraseology, like later love songs".

8 Fowler (1987: 7).

9 Cf. Campbell (1983: 5) e Burnett (1983: 80). Dover (1964: 197) foi o primeiro que criticou, com razão, Bonnard (in Lasserre e Bonnard, 1958) por traduzir o fragmento "como se o poeta falasse de si". 
Mas não só ignoramos quem fala e de quem fala, como nada sabemos do contexto, embora quase todos relacionem os versos à narrativa de Arquíloco e as filhas de Licambes, supondo que "Arquíloco" declarasse, em $1^{\text {a }}$ pessoa, seu amor por Neobula ${ }^{10}$.

Por que o sujeito não poderia ser um homem falando de uma mulher, ou inclusive uma mulher falando de si? Croiset (19132: 189) e Campbell (1983: 6) já aventaram a primeira possibilidade ${ }^{11}$. Se quisermos manter o cenário geralmente eleito (o da "Saga das Licâmbides"), uma candidata, nesse caso, seria Neobula (ou uma de suas irmãs), que "Arquíloco" censura. Mas nada impede que o falante fosse uma mulher e, nesse caso, os versos poderiam ser reminiscências da velha Neobula (cf. $188 I E G^{2}$ ), lamentando eventos passados.

Em termos de linguagem, apesar de todos reconhecerem nesses versos vários elementos presentes na épica, as interpretações diferem radicalmente. Para alguns, cada frase seria a imitação de uma fórmula ou de um verso homérico específico. Por exemplo, segundo Page (1964: 138-9), a linguagem do fragmento é "inteiramente tradicional", o poema chegando a ser uma "concatenação de fórmulas épicas adaptadas aos novos metros" e "não havendo nada de novo no espírito ou no conteúdo dos versos": "a atualidade do tema, se é que ele é atual - não faz diferença alguma no modo ou em que se diz"12. Para Marzullo (1967²: 32), Arquíloco apresenta um realismo conceitual "severamente inscrito no modelo épico".

Outros supõem que o fragmento faça novo emprego de material homérico $^{13}$. Degani e Burzacchini $\left(2005^{2}\right.$ : 32), sem atenuar o "homerismo" dos versos, alegam que neste poema Arquíloco canta o amor com "novidade e intensidade de acentos", "com nítida, essencial imediatez que claramente antecipa Safo" ${ }^{14}$, assim como também no fragmento 193 IEG $^{2}$.

10 Segundo Lasserre (in Lasserre e Bonnard, 1958), o fragmento evoca o tempo em que o poeta era apaixonado por Neobula. No entanto, para outros, ele expressa amargura (Kirkwood, 1974: 41: "love turned to bitterness".) Para Hauvette (1905: 230), "Arquíloco" cogita em vingar-se. Gerber (1970: 41) lê os versos como crítica que o poeta dirige a se próprio por sua tolice, por ter-se deixado cegar por amor.

11 Campbell (1983: 6), aparentemente com o intuito de explicar o emprego do epíteto "frágil", ou "delicado", para a "mente" do sujeito no terceiro verso ("frágil juízo"), diz: "if the passage is about a girl in love, the word may have been chosen as applicable to the weaker sex - her tender wits; ..."

12 Cf. Barron e Easterling (1985: 82).

13 Broccia (1969: 92). Para Kirkwood (1974: 42), as frases de Arquíloco, por evocarem incidentes homéricos, ganham força pelo contraste.

14 Veja também Gentili e Catenacci $\left(2007^{3}: 104\right)$ para a comparação de Arquíloco 191 IEG $^{2}$ com Safo $2 \mathrm{~V}$. 
Fowler (1987: 25-26), por outro lado, reconhece os elementos tradicionais que constituem o poema, mas se recusa a julgar que, ao compor os versos, Arquíloco recorresse deliberadamente a uma palavra ou frase dos poemas épicos, tendo em mente uma passagem específica e com o intuito de criar efeitos intertextuais, como fizeram os poetas tardios.

Restam-nos, portanto, várias perguntas sem resposta: quem fala, de quem fala, e o contexto do poema como um todo.

v.1

O primeiro verso inicia-se com toĩoc, um termo poético ${ }^{15}$ que, apesar de ser um correlativo, emprega-se também de forma absoluta em Homero $^{16}$ como, talvez, nesse poema (Marzullo, 1967²:32).

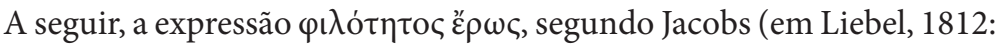

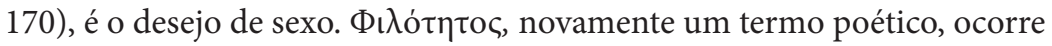
em Homero geralmente no sentido de amor sexual ${ }^{17}$ e, para $\varepsilon^{\prime} \rho \omega \varsigma^{18}$ como “desejo", Brunck (1772) cita o paralelo em Sófocles, Édipo em Colona $367^{19}$. No entanto, nessa expressão, "desejo de eros", qual o valor do genitivo? A frase é ambígua, porque podemos entender que o desejo tem sua origem em Eros ou é de Eros (possessivo) ou que se trata do desejo por eros = amor/sexo (genitivo objetivo) ${ }^{20}$.

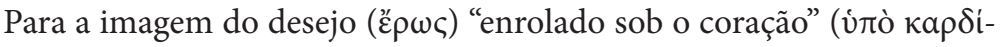
$\eta \nu \dot{\varepsilon} \lambda v \sigma \theta \varepsilon \grave{c})$, todos citam o episódio homérico em que Odisseu escapa da caverna do Ciclope agarrado a um carneiro, "enrolado sob o ventre" (Od.

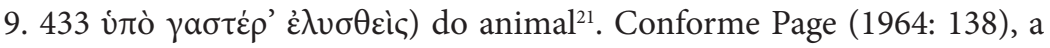
frase de Arquíloco é uma adaptação da fórmula homérica $(O d .9 .433)^{22}$, e

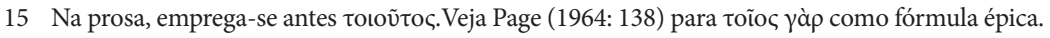

16 Il. 4. 289, 390, 399 etc.

17 Cf. Liebel (1812: 170), Hauvette (1905: 230), Marzullo (1967²: 32), Degani e Burzacchini (2005²:

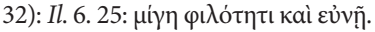

18 Marzullo (1967²:32) nota que, na épica, époc é mais comum que é $\rho \omega \varsigma$, a forma empregada por Arquíloco.

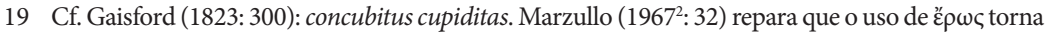

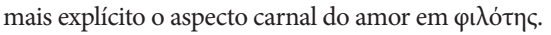

20 Cf. Gerber (1970: 41) e Campbell (1983: 6).

21 Kirkwood (1974: 42) e Carson (1986: 47) citam como paralelo a cena da Ilíada 24. 510 na qual

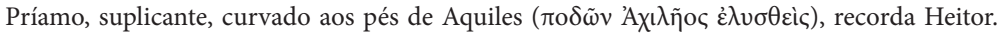
Assim também, a leitura de Burnett (1983: 80) parece depender desse paralelo.

22 Veja também Marzullo (1967²: 32), Broccia (1969: 87), Degani e Burzacchini (2005²: 32). 
alguns que consideram a imagem uma referência explícita ao episódio de Odisseu e do Ciclope supõem um certo humor da parte do poeta ao comparar o coração com o ventre. ${ }^{23}$ Marzullo (19672: 32) acredita que o passo dependa estruturalmente de Homero e que em Arquíloco o "rigor formal pareceria forçado, não fosse uma imagem ousada": a do amor enrolado sob o coração, como Odisseu sob o ventre do carneiro. Para Degani e Burzacchini $\left(2005^{2}: 32\right)$, é desconcertante que Arquíloco, ao criar uma nova e poderosa imagem, tenha emprestado de Homero não apenas os termos e as expressões, mas inclusive a cena de Odisseu. Já observamos que Fowler (1987: 25), porém, não supõe que Arquíloco pretendesse evocar, com essa frase, o episódio homérico na mente dos seus ouvintes, não obstante a força da imagem nos dois poemas.

Portanto, embora não haja consenso quanto à referência explícita ou não a Homero, todos concordam que representar o "desejo de amor" como algo "enrolado sob o coração" seja uma forma surpreendentemente plástica e vigorosa de figurá-la, e uma imagem extraordinária ${ }^{24}$. No pensamento e na poesia arcaica, desejo é Eros, mas a sua presença, no cerne do sujeito, é concebida por Arquíloco como algo que se instala sob o coração ( $\left.\alpha \alpha \delta i \eta^{25}\right)$.

Outro passo homérico recordado por Liebel (1812: 170), não por uma semelhança formal, mas de sentido, é o do chamado "engano de Zeus", no décimo-quarto canto da Ilíada, quando o Zeus chama Hera para o leito (Il. 14. 315-16):

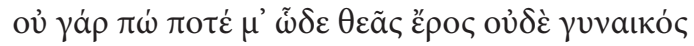

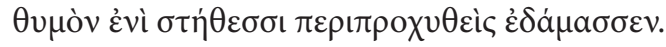

"Eros jamais, por deusa ou mulher, desse modo circunflamou meu coração e o domou no peito." ${ }^{26}$

Cita-se também com freqüência o verso do Escudo de Héracles 41, considerado por Marzullo (1967²: 32) como imitação de Arquíloco. Anfitrião, ao retornar de seus trabalhos, procurou imediatamente a sua esposa:

23 Cf. Campbell (1983: 6) e Harvey in Fowler (1987: 26): “Archilochus' manner throughout is ironic or, as Harvey says, mock-heroic."

24 Cf. Marzullo (1967²: 32), Broccia (1969: 87), Degani e Burzacchini (2005²: 32), Fowler (1987: 26).

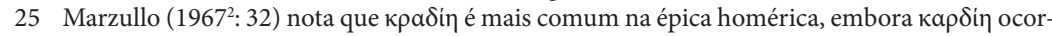
ra em Il. 2. 452, 11. 12, 14. 152.

26 Tradução de Haroldo de Campos (2002), ligeiramente modificada. 


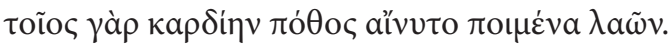

"pois tal anseio apoderou-se do coração do pastor das tropas".

Nícias, AP 7. 200.1, e Apolônio de Rodes, 3. 281, 296, são citados como emulações helenísticas de Arquíloco. Mas o verso de Nícias (AP 7. 200.1:

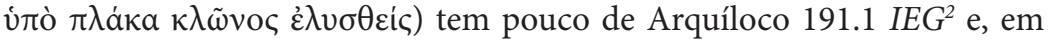
Apolônio de Rodes 3. 281, quando Eros se enrola aos pés de Jasão (ن́rò

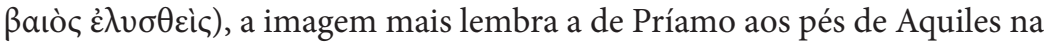
Ilíada 24. 510 (cf. nota 20 supra). No entanto, em seguida, quando o narrador em Apolônio 3. 296-8 retrata Eros, pernicioso, enrolado sob o coração de Medeia, os versos apresentam vários elementos presentes em Arquíloco $191 I E G^{2}$. Há o correlativo toĩo no início do verso, a expressão "enrolado

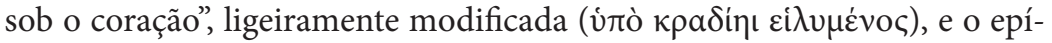
teto áđa入ác ("frágil"), que em Apolônio qualifica as faces, não o juízo da vítima de Eros (3.296-8):

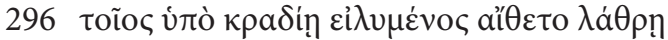

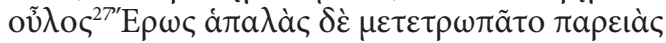

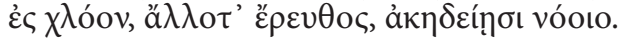

"desta forma, sob seu coração se envolvendo, ardia secretamente o funesto Eros. E seu tenro rosto se transformava, ora pálido, ora ruborizado, com o entorpecimento de sua razão."28

Em Arquíloco $191 I^{2} G^{2}$, como em Apolônio 3. 298, Eros acarreta o prejuízo da razão (vóoc), e semelhança dos passos pode dar força a um argumento a favor de uma personagem feminina em Arquíloco 191 IEG ${ }^{2}$, ao qual Apolônio estaria comparando Medeia.

v.2

No segundo verso de Arquíloco $191 I E G^{2}$, descreve-se a ação do "desejo de amor" que, a partir de sua posição central e interna, enrolado sob

27 Seria fortuita a ambiguidade suscitada pelo adjetivo oũ $\lambda$ o empregado para caracterizar Eros, uma vez que oũ $\lambda$ o s significa "destrutivo", pernicioso (A), ou "lanoso" (B), como a lã do carneiro (Aristóteles HA 596 b 6), o que pode evocar o episódio da fuga de Odisseu sob o carneiro do Ciclope (Od. 9)?

28 Tradução de F. Rodrigues Jr. (2005). 
o coração da personagem, age sobre membros periféricos: "muita névoa dos olhos vertia". O emprego do imperfeito sublinha o caráter repetitivo ou paulatino da ação do desejo que ofusca a vista.

Safo $31 \mathrm{~V}$ descreve a cegueira que a amante sofre ao ver sua amada: "com os olhos nada vejo" (ỏ $\pi \pi \alpha \dot{\tau} \varepsilon \sigma \sigma \iota \delta^{\prime}$ ov̉ $\left.\delta^{\prime} \varepsilon \dot{v} v \dot{u} \pi \alpha \delta \varepsilon \delta \rho o ́ \mu \eta \kappa \varepsilon v\right)$, além de outros efeitos físicos que a aproximam da sensação de morte. Em Arquíloco 191. $2 I_{E G^{2}}$ é espessa névoa ${ }^{29}$ que Eros derrama sobre os olhos do/a amante, se-

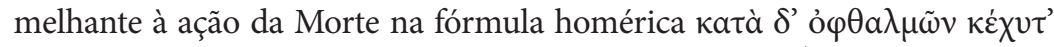
ảx入úc: Il. 5. 696 (onde o herói quase morre) e 16. 344 ${ }^{30}$. É também no con-

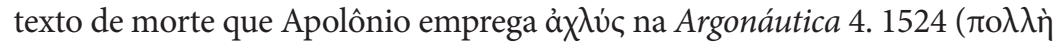

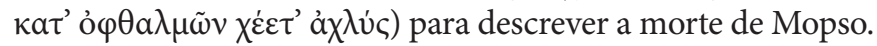

Que os olhos sejam veículos do amor é lugar comum na literatura grega, assim como é frequente a noção de que Eros neles resida. Em Arquíloco $191 I E G^{2}$, porém, Eros instala-se enrolado sob o coração do sujeito e o debilita, impedindo o funcionamento normal de órgãos de percepção (olhos)

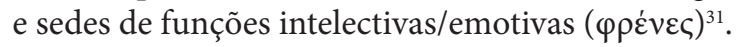

Alguns consideraram a expressão de Arquíloco, "névoa sobre os olhos

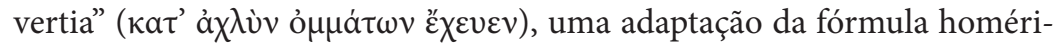
$\mathrm{ca}^{32}$. Nota-se, porém, que na Ilíada a névoa se espalha sobre os olhos na proximidade da morte (Il. 5. 696), ou com a própria morte (Il. 16. 344), e sobre os olhos de quem vê a morte de um ente querido (Il. 20. $421^{33}$ ), ou ainda por agência de Poseidon (Il. 20. 321), mas não por $\operatorname{Eros}^{34}$.

Portanto, se na tradição poética jônica anterior a Arquíloco a frase era comum para descrever a morte de guerreiros, ao inseri-la em contexto de

29 Marzullo (1967²: 32): o substantivo ảxגúc é geralmente usado no sentido figurado, como aqui, e significa "névoa" propriamente apenas na Odisseia 7. 41, 19. 357. Arquíloco emprega a forma ỏ $\mu \alpha \dot{\alpha} \tau \omega v$ e não ỏ $\varphi \theta \alpha \lambda \mu \tilde{\omega} v$ por motivos métricos, segundo Page (1964: 138).

30 Em contexto diverso, em Il. 20.321, Poseidon derrama névoa sobre os olhos de Aquiles para

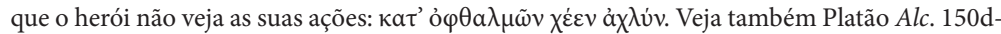
e para a névoa (ảx $\lambda$ ús) que ofusca a razão. Em Crítias 6. 10-12 IEG ${ }^{2}$, névoa encobre os olhos, perde-se a memória e a razão por excesso de vinho e, em Apolônio 3. 725-6 poivíx $\theta \eta \delta^{\prime}$ ă $\mu v \delta ı \varsigma$

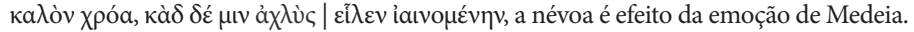

31 Posteriormente, entre I a. C. - I d. C., em Cáriton, Caliroé 2.4 e 3.3, a névoa (ảx $\lambda u ́ c)$ encobre os olhos de Dionísio por efeito de forte emoção.

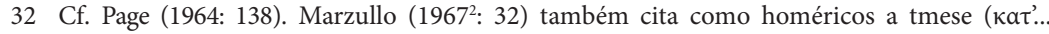

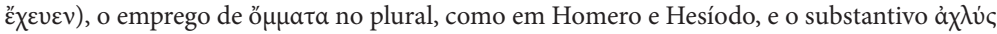

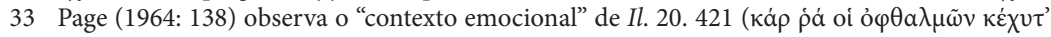
ảx $\lambda \dot{u} \varsigma$ ): Heitor vê Polidoro, com as entranhas nas mãos, rolar por terra e morrer. A imagem da névoa cobrindo os olhos, empregada em associação com a morte em Il. 5. 696, 16. 344, Od. 20. 357, 22. 88, ocorre em Il. 20. 421 para quem contempla a morte.

34 Para a associação de ảx $\lambda$ úc com a morte, veja ainda o Escudo 264, Ésquilo Pers. 669 e Nono Dion. 28. 109. 
poesia amatória, Arquíloco não apenas acena para a associação entre Eros e morte, como também evoca o contexto do amor como guerra: Eros age como um guerreiro que, em emboscada (enrolado sob o coração ${ }^{35}$ ), tolhe a visão e espolia o juízo do peito. A linguagem épica assemelha o/a amante a um guerreiro que sucumbe. Esse recurso é mais explícito no fragmento $193 I E G^{2}$, examinado a seguir.

É notável que, ao narrar na Argonáutica como os olhos de Medeia se

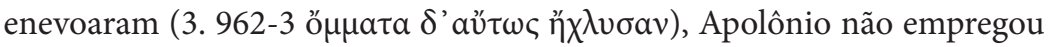
a imagem em seu contexto épico mais comum, isto é, na ocasião de morte de guerreiros, mas para descrever os efeitos de uma paixão amorosa, como o fizera Arquíloco:

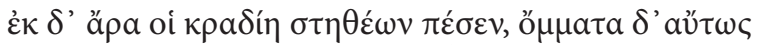

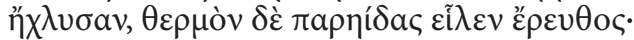

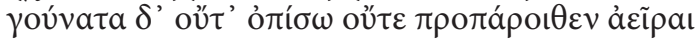

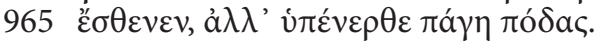

"Seu coração saltava do peito, seus olhos

cobriam-se de névoa, um rubor quente lhe tomava as faces.

Para erguer os joelhos nem para trás nem para frente

965 tinha força, mas havia um laço sob seus pés." ${ }^{36}$

v.3

Embora sejam atos distintos, o sequestro do "frágil juízo do peito" no terceiro verso relaciona-se com a cegueira descrita no verso anterior: após ter furtado $\left(\kappa \lambda \dot{\varepsilon} \psi a \varsigma^{37}\right)$ o juízo, a névoa é vertida no que não parece ser simples sequência temporal, mas em efeito causal. É como se os olhos fossem obscurecidos porque o juízo foi espoliado do corpo ${ }^{38}$.

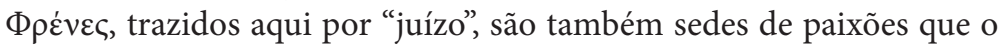
"desejo de amor" retira de dentro do "peito" ( $\left.\sigma \tau \eta \theta \dot{\varepsilon} \omega \nu^{39}\right)$. Esse "juízo" é qualificado pelo adjetivo áđa入ós ("frágil”, "delicado"), que se emprega em

35 Marzullo (1967²: 32) compara a frase "enrolado sob o coração" com a imagem do guerreiro agachado, protegido sob o seu escudo Il. 13. 405, Calino 1. $10 I^{2} G^{2}$.

36 Tradução de F. Rodrigues Jr. (2005), ligeiramente alterada.

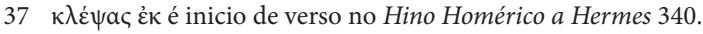

38 Para Broccia (1969: 89), ao contrário, há simultânea perda de visão e razão, e ele cita como exemplos homéricos dessa simultaneidade Il. 14. 518, 22. 466.

39 Page (1964: 138) nota que a forma do genitivo plural empregado ( $\sigma \tau \eta \theta \dot{\varepsilon} \omega v)$ é habitualmente evitada na épica homérica, ocorrendo apenas em Il. 10. 94. 
Homero geralmente para as partes do corpo humano, mas que também

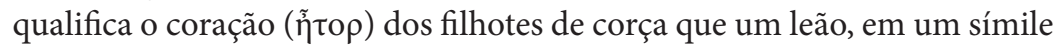
iliádico, arranca, Il. 11. 115:

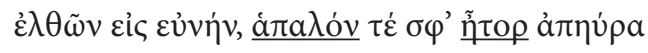

"...no redil, lhes retira o tenro coração" 40 .

Na hipótese de que os versos se refiram a uma jovem (Neobula, ou sua irmã mais moça?), a tenra idade e inexperiência contribuiriam para a fragilidade de seu juízo.

O epíteto áđa入óc em Arquíloco $191 I^{2} G^{2}$ foi vertido de diversas maneiras $^{41}$. Broccia (1969: 90) não o considera como um atributo permanente e constitutivo dos $\varphi \rho \varepsilon ́ v \varepsilon \varsigma$, mas circunstancial. Eros é o que os torna "frágeis". É também possível que o adjetivo tenha por função contrastar a impotência (ả $\left.\mu \eta \chi \alpha v^{i} \alpha\right)$ do juízo humano diante da força de Eros que o subjuga ${ }^{42}$. Na Ilíada, por exemplo, Páris chama Helena para o leito (Il. 3. 442):

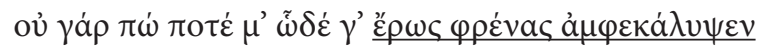

“....................que Eros, nunca, tanto me enublou

de paixão os sentidos;..."

No episódio do "engano de Zeus", Afrodite entrega a Hera um cinto mágico para que ela seduza Zeus (Il. 14. 216-7):

40 Tradução de Haroldo de Campos (2002). É possível que o adjetivo ára入óv qualifique o coração de animais nesses versos homéricos por se tratar de um símile. Termos habitualmente empregados para os seres humanos também se referem a animais no símile das águias na Ilíada e no Agamêmnon de Ésquilo (cf. Corrêa 2010: 47-118). Kirkwood (1974: 42) nota que o adjetivo emprega-se usualmente para as partes externas do corpo e que a transferência operada por Arquíloco é forte.

41 Segundo Gerber (1970: 41), o adjetivo em Arquíloco 191 IEG ${ }^{2}$ significa "fraco" ou "frágil", não "tenro". Totalmente diversa é a interpretação de Hauvette (1905: 229) que lê ả verte como "vigoroso". Em diversos passos, o epíteto ả $\tau a \lambda o ́ \varsigma$ qualifica como "tenra" a mente dos jovens, como no símile supracitado (Il. 11. 115). Nesse sentido, veja também Il. 18. 567,

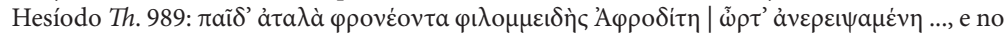

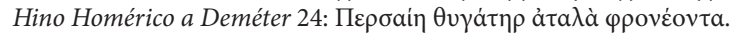

42 Cf. Arquíloco 196 IEG ${ }^{2}$.

43 Trad. Haroldo de Campos (2002). Veja também a fala de Zeus (Il. 14. 315-6). 


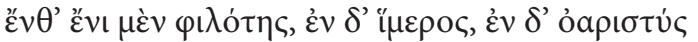

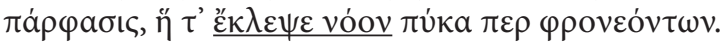

“... lá

o amor e o impulso de eros; o enlace de núpcias

e o enlevo sedutor, que mesmo aos sábios faz perder o juízo." 44

Como bem argumenta Fowler (1987: 25), não se deve supor que esses versos de Homero fossem o modelo de Arquíloco $191 I G^{2}$, cuja formulação revela diferenças. Fowler (loc. cit.) nota ainda que o verso homérico é gnômico e que a "capacidade do amor ludibriar suas vítimas já seria tradicional" ${ }^{45}$. A freqüência com que a expressão "roubo da mente" ( $\kappa \lambda \dot{\varepsilon} \psi \alpha$ เ vóov) ocorre indica um "lugar comum", presente não apenas em Homero, mas também na Teogonia hesiódica $613^{46}$, Semônides 42 IEG ${ }^{247}$ e nas Coéforas $854^{48}$ de Ésquilo.

A descrição do amor como algo exterior ao sujeito, que o desmembra, subtrai a mente e confunde os sentidos, encontra-se na literatura grega desde Homero. Embora tais elementos sejam apontados como mais tipicamente "líricos" 4 , vimos como o poeta já teria a seu dispor, na tradição épica jônica, noções e expressões semelhantes a essas. Assim, um efeito do recurso à linguagem épica no fragmento $191 I E G^{2}$ é a associação de Eros com a morte, e do amante com o guerreiro.

Arquíloco Fr. 193 IEG²: Estobeu 4. 20.45

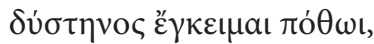

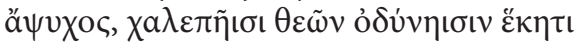

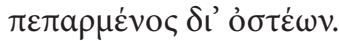

"mísero estou, com desejo, sem vida, com dores atrozes, por vontade divina, trespassado até os ossos."

44 Tradução de Haroldo de Campos (2002).

45 O significado da frase em Il. 1. 132, citado como um paralelo por Fowler (1987: 25), é, porém, diverso: não é o sujeito que se vê privado da razão, mas ele próprio é quem "oculta suas intenções", como Hermes (Hino Homérico a Hermes 413).

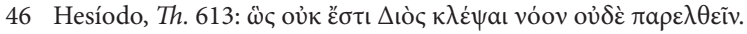

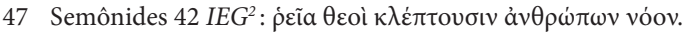

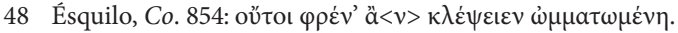

49 Cf. Fowler (1987: 26) e Arquíloco 196, $193 I^{2} G^{2}$; Safo 1. 31 V, Anacreonte 413 PMG. 
Assim como o fragmento $191 I_{E G^{2}}$ de Arquíloco, esses versos também tem como fonte única Estobeu, que os arrolou entre os poemas Sobre Afrodite (4. 20.45). Outra característica que partilham com o fr. $191 I E G^{2}$ é o imaginário, proveniente da associação do amor com a morte e do amante com o guerreiro ${ }^{50}$.

\section{v.1}

A primeira palavra do fragmento anuncia o tom do poema: "mísero"

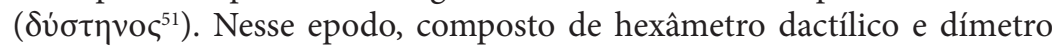
jâmbico, ao contrário do que ocorre no fragmento $191 I E G^{2}$, temos indiscutivelmente uma declaração do sujeito em primeira pessoa do singular

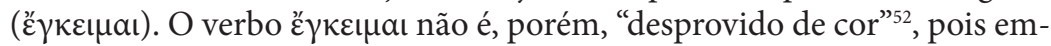
prega-se para o que envolve os mortos (Il. 23. 513, Heródoto $2.73^{53}$ ), além

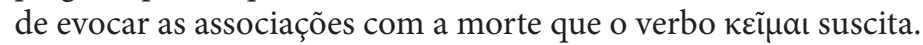

O sujeito está prostrado "com desejo" ( $\pi$ ó $\theta \omega \mathrm{\iota})^{54}$. Marzullo $\left(1967^{2}: 31\right)$ e Gerber (1970: 40) notam que em Homero tó $\theta$ oc é saudade, nostalgia, não desejo, como em Arquíloco. Mas saudade é desejo do que está distante no tempo ou espaço. Assim, pode-se dizer que ró $\theta$ oc é também uma forma de desejo ${ }^{55}$. No verso $196 I E G^{2}$, Arquíloco revela a força desmembradora de $\pi$ ó $\theta$ os sobre o sujeito:

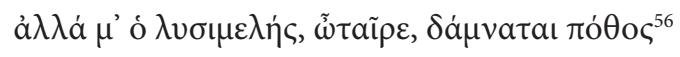

"Mas o desejo solta-membros, ó companheiro, subjuga-me"

50 Lasserre (1950: 185) supunha que os versos teriam inspirado Horácio no início de seu Epodo 14, composto no mesmo esquema métrico e, consequentemente, ele insere esse fragmento em sua restauração de Arquíloco, Epodo 12, que consistiria apenas desse fragmento e de um testemunho de Malalas (p. 68.1 Dindorf, fr. 305). Adrados (1990³: 52) discorda da interpretação de Lasserre e sugere que o fragmento talvez fizesse parte do epodo seguinte, no qual o poeta teria ameaçado os seus rivais com a narrativa da morte de Neso.

51 Page (1964: 141), que considera a fraseologia do fragmento uma "adaptação e extensão de

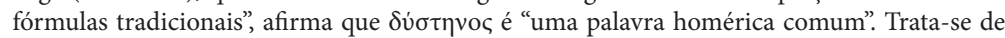
um termo poético que qualifica, aqui e em Homero, seres humanos (Marzullo, 1967²: 31).

52 Campbell (1983: 5).

53 Page (1964: 141) considera o emprego desse verbo com o dativo como uma das poucas inovações no poema.

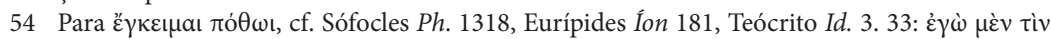
ö ber, 1970: 40, e Gentili-Catenacci $\left.2007^{3}\right)$.

55 Cf. Burnett (1983: 80).

56 Hefestião Ench. 15. 9.

Organon, Porto Alegre, v. 31, n. 60, p. 47-62, jan/jun. 2016. 
Nas Mulheres na Assembléia de Aristófanes 956-7, a moça que deseja

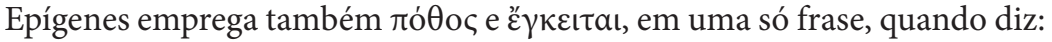

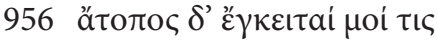

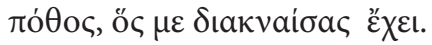 \\ "extraordinário é o desejo que em mim \\ jaz, que me lacera e possui."
}

Essa é a primeira ocorrência de termo ä $\psi v \chi 0 \varsigma$ ( "sem vida" ou, mais literalmente, "sem-psykhé") na literatura supérstite e o segundo epíteto usado pelo sujeito para se descrever ${ }^{57}$. Neste fragmento de Arquíloco, mais claramente do que em $191 I^{2} G^{2}$, o estado do amante compara-se com a morte, momento em que a psykhé, o sopro de vida, deixa o corpo pela boca, pelas narinas ou feridas, e parte para o Hades.

Da tradição épica jônica vem o uso do adjetivo $\chi a \lambda \varepsilon \pi$ ó ("atroz") para

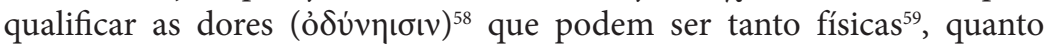
mentais ${ }^{60}$. Que essas dores - efeito do desejo - são enviadas pelos deuses,

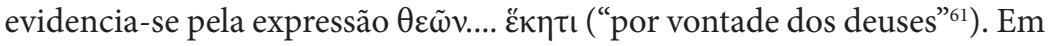

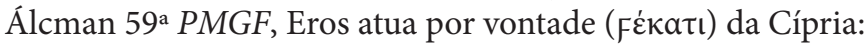

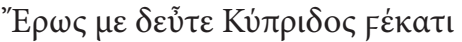

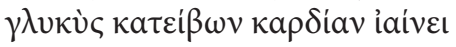

"Eros, novamente, por vontade da Cípria,

Derramando-se, doce, aquece-me o coração."

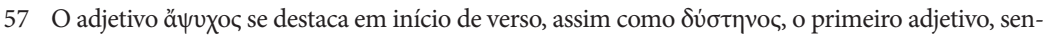
do os dois trissílabos que rimam em -os e têm assonância em úpsilon.

58 No Hino Homérico a Apolo 358, atrozes são também as dores da serpente Tifão, trespassada

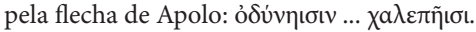

59 Od. 9. 440, 17. 567; Il. 11. 398, etc.

60 Il. 15. 25; Od. 1. 242, 2.79 etc.

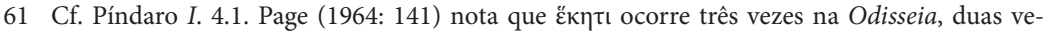

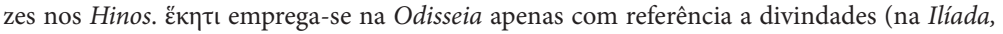
ió $\eta \tau \iota)$, frequentemente posposto, mas na lírica e tragédia refere-se também a objetos. Em

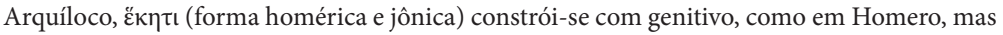
o digama não é observado. 
Mas, ao contrário do que ocorre em Arquíloco 193 IEG², em Álcman

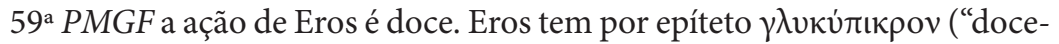
-amargo") em Safo 130 V, mas nestes versos de Arquíloco ele revela o seu aspecto mais acerbo.

\section{v.3}

$\mathrm{Na}$ épica jônica, a descrição do guerreiro com os ossos trespassados por espadas, lanças ou flechas é frequente ${ }^{62} \mathrm{e}$ a expressão "trespassada por dores" ocorre, posteriormente, em outros contextos ${ }^{63}$. Mas a imagem dos ossos trespassados por dores de amor ou por desejo não é comum no período arcaico ${ }^{64}$. Portanto, Arquíloco recorre a uma expressão da narrativa marcial para descrever a agonia do amante. Se no primeiro verso e no início do segundo o desejo afeta a alma, deixando o sujeito infeliz e "sem ânimo", no restante do segundo e terceiro versos, as dores que causa são físicas e lancinantes, atravessando-lhe os ossos.

Para Kirkwood (1974: 42-43), o fragmento $193 I E G^{2}$ é uma "afirmação altamente pessoal e não-épica”, e ele compara os versos de Arquíloco com a Ilíada 5. 399, da qual ele acredita que o segundo verso do poeta pário "venha diretamente". No entanto, apesar das semelhanças entre Arquíloco 193. 2 IEG ${ }^{2}$ e a Ilíada 5. 399, é difícil supor tratar-se de alusão deliberada; há outras expressões comparáveis na Ilíada (cf. nota 61), no Hino Homérico a Apolo, e nenhum dos paralelos citados é idêntico.

Muitos apontaram para as fortes imagens por meio das quais se expressa o desejo amoroso nos fragmentos 191 e 193 IEG de Arquíloco, que antecipariam as de poetas líricos posteriores e, particularmente, as de $\mathrm{Safo}^{65}$. Nesses dois fragmentos, Arquíloco apresenta os efeitos negativos do amor e do desejo que subjuga o sujeito, prejudica suas capacidades, visão e juízo, infligindo-lhe dores tanto na carne, quanto no espírito, pois em Arquíloco a dor é também física, atravessa os ossos.

62 Cf. Il. 4. 460, 11. 97: o golpe de Agamêmnon vara seu adversário Si’... ỏotéov. Alguns consideram a frase em Arquíloco formular, citando Il. 5. 399 sobre Hades, trespassado por flecha

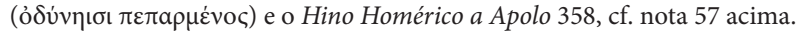

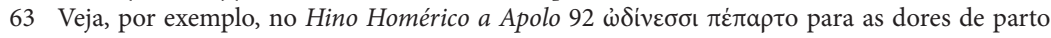

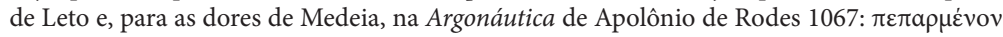

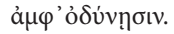

64 As primeiras ocorrências supérstites das flechas de Eros ocorrem no período clássico, em Eurípides, I.A. 548-9, Hipp. 530.

65 Hauvette (1905: 229, 252), Lasserre e Bonnard (1958), Marzullo (1967²: 31), Gerber (1970: 40), Campbell (1983: 5) e Fowler (1987: 26). 


\section{BIBLIOGRAFIA}

ADRADOS, F. R. Líricos Griegos I: Elegiacos y Yambógrafos Arcaicos. Barcelona: Alma Mater, 1956-1959 (1a ed.). Madri: Consejo Superior de Investigaciones Científicas: 1990 (3a ed.).

BARRON, J. P. e EASTERLING, P. E. Archilochus. in P. Easterling e B. M. W. Knox, The Cambridge History of Classical Literature I. Greek Literature. Cambridge: Cambridge University Press, 1985.

BERGK, T. Poetae Lyrici Graeci, vol II. Leipzig, B. G. Teubner, 1882 (4a ed.), 1915.

BOWIE, E. "One that got away: Archilochus 188-192W and Horace, Odes 1.4 e 5”, em Homo Viator: Classical Essays for John Bramble. Bristol: Bristol Classical Press; Oak Park: Bolchazy-Carducci, 1987. p. 13-23.

BROCCIA, G. Tradizione Ed Esegesi: Studi Su Esiodo E Sulla Lirica Greca Arcaica. Brescia: Paideia, 1969.

BRUNCK, R. F. P. Analecta Veterum Poetarum Graecorum. Estrasburgo: Argentorati, 1772, vol. I.

BURNETT, A. P. Three Archaic Poets: Archilochus, Alcaeus, Sappho.

Londres: Duckworth, 1983.

CAMPBELL, D. A. The Golden Lyre; the Themes of the Greek Lyric Poets. Londres: Duckworth, 1983.

CAMPOS, H. de. Ilíada de Homero. Trad. São Paulo: Mandarim, 2001, vol. I.

CAMPOS, H. de. Ilíada de Homero. Trad. São Paulo: Arx, 2002, vol. II. CARSON, A. Eros the Bittersweet: An Essay. Princeton: Princeton University Press, 1986.

CORRÊA, P. Da Cunha, Um Bestiário Arcaico. Fábulas e imagens de animais na poesia de Arquíloco. Campinas: Editora Unicamp, 2010. CROISET, A. e M. Histoire de la littérature grecque. Paris: E.Thorin, 1913 (2a Ed.).

DAVIES, M. Poetarum Melicorum Graecorum Fragmenta. New York: Oxford University Press, 1991.

DEGANI, E. e BURZACCHINI, G. Lirici Greci. Agg. bibliografico a cura di M. Magnani. Bologna: Pàtron Ed., 2005 (2a ed.).

DOVER, K. J. "The Poetry of Archilochus", in POUILLOUX, 1964, p. 183-212.

De FALCO, V. e A. de FARIA COIMBRA, Os Elegíacos Gregos de Calino a Crates. São Paulo: Brusco, 1941.

FICK, A. F. Die Sprachform der altionischen und altattischen Lyrik, in Beiträge zur Kunde der Indogermanischen Sprachen, 13, 1888, p. 173-221. 
FOWLER, R. L. The Nature of Early Greek Lyric. Three Preliminary

Studies. Toronto, Buffalo: University of Toronto Press, 1987.

FRÄNKEL, H. Early Greek Poetry and Philosophy: a history of Greek epic, lyric, and prose to the middle of the fifth century. Trad. M. Hadas e J. Willis. Oxford: Basil Blackwell, 1975.

GAISFORD, T. Poetae Minores Graeci. Leipzig: Kühn, 1823, vol. I. GENTILI, B. e C. CATENACCI. Polinnia; Poesia Greca Arcaica. MessinaFirenze: Casa Editrice G. D’Anna, 2007 ( $3^{\mathrm{a}} \mathrm{ed}$.).

GERBER, D. E. Euterpe: An Anthology of Early Greek Lyric, Elegiac and Iambic Poetry. Amsterdã: Adolf M. Hakkert, 1970.

HAUVETTE, A. Archiloque, sa vie et ses poésies. Paris: Fontemoing, 1905. HILLER, E. Anthologia Lyrica Graeca sive Lyricorum Graecorum Veterum praeter Pindarum. Leipzig: B. G. Teubner, 1890.

HOFFMANN, O. Die griechischen Dialekte in ihrem historischen Zusammenhange (III): Der Ionische Dialekt. Göttingen: Vandenhoeck \& Ruprecht, 1898.

KIRKWOOD, G. M. Early Greek Monody. Ítaca e Londres: Cornell University Press, 1974.

LASSERRE, F. Les Épodes d' Archiloque. Paris: Belles Lettres, 1950. LASSERRE, F. e BONNARD, A. Archiloque: Fragments. Paris: Belles Lettres, 1958.

LIEBEL, I. Archilochi Reliquiae. Leipzig, Sommer, 1812; Viena: Johann Bartholomäus Zweck, 1812, 1818 (2a ed.). MARTINS de JESUS, C. A., Arquíloco; Fragmentos Poéticos. Lisboa: Imprensa Nacional - Casa da Moeda, 2008. MARZULLO, B. Frammenti della lirica greca. Florença: Sansoni, 19651967 (2a ed.).

PAGE, D. L., "Archilochus and the Oral Tradition", in POUILLOUX, 1964, pp. 118-79.

POUILLOUX, J. et al. Archiloque: Sept exposés et discussions. "Entretiens sur l'Antiquité Classique X” (Vandoevres, Genebra, 26/8-3/9/1963).

Genebra: Fondation Hardt, 1964.

RODRIGUES Jr., F., Epopéia e Poesia Alexandrina: Estudo e Tradução do Canto III das Argonáuticas de Apolônio de Rodes. Dissertação de mestrado em Letras Clássicas, USP, FFLCH-DLCV, 2005.

SNELL, B. Die Entdeckung des Geistes; Studien zur Enstehung des europäischen Denkens bei den Griechen. Göttingen: Vandenhoeck und Ruprecht, 1993 (7a ed.).

TARDITI, G. Archiloco. Roma: dell' Ateneo, 1968. 
WEST, M. L. Studies in Greek Elegy and Iambus. Berlim, Nova York: de Gruyter,1974.

Siglas de edições:

IEG ${ }^{2}$ WEST, M. L., Iambi et Elegi Graeci ante Alexandrum cantati. Oxford University Press, Oxford, 1998 (2 $2^{a}$ edição)

PMGF - DAVIES, M. Poetarum Melicorum Graecorum Fragmenta. Oxford University Press, New York, 1991.

V - VOIGT, E.-M., Sappho et Alcaeus. Athenaeum-Polak \& Van Gennep, Amsterdam, 1971.

Recebido em: 30/11/2015. Aceito em: 01/03/2016. 